\title{
Interpreting life cycle assessment results for integrated sustainability decision support: can an ecological economic perspective help us to connect the dots?
}

\author{
Nathan Pelletier ${ }^{1}$ (D) Nicole Bamber ${ }^{1} \cdot$ Miguel Brandão $^{2}$
}

Received: 7 January 2019 / Accepted: 8 March 2019 / Published online: 26 March 2019

(C) The Author(s) 2019

\begin{abstract}
Life cycle assessment (LCA) is often described as a sustainability decision support tool. In practice, however, the interpretation and application of most LCA studies are restricted to eco-efficiency considerations, which provide an important but incomplete basis for sustainability decision-making. Recent methodological advances in the field enable assessing LCA results against sustainability boundaries or thresholds at planetary or more finely resolved scales. Weighting, although controversial, facilitates consistent, stakeholder-appropriate decision-making that reflects prioritization among multiple and potentially competing sustainability outcomes. Here, we discuss how the three minimum necessary criteria for sustainability (i.e., sustainable scale relative to biocapacity, distributive justice, and efficient allocation), as proposed by ecological economist Herman Daly, may provide an internally consistent basis for integrating these methodological developments, and for subsequently better positioning LCA as a sustainability decision support framework.
\end{abstract}

Keywords Distributive justice · Efficiency $\cdot$ Interpretation $\cdot$ Life cycle assessment · Planetary boundaries · Sustainability Weighting

\section{Introduction}

Broadly conceived, sustainability refers to ensuring maintenance of the conditions necessary to our individual and collective well-being, within and across generations. These conditions span what will often be a plurality of interacting and mutually-constituting considerations in the biophysical, ecological, socio-economic, political, cultural, psychological, spiritual/esthetic, and other realms. In light of these multiple

Responsible editor: Mary Ann Curran

Nathan Pelletier

nathan.pelletier@ubc.ca

1 340, Fipke Centre for Innovative Research, University of British Columbia Okanagan, 3247 University Way, Kelowna, BC V1V1V7, Canada

2 Department of Sustainable Development, Environmental Science and Engineering (SEED), School of Architecture and the Built Environment (ABE), KTH - Royal Institute of Technology, Stockholm, Sweden facets of sustainability, the variety of objectives that might be invoked in their pursuit, and the potential context-specificity of prioritizing among them, sustainability as a normative goal for society represents the quintessential wicked problem.

Indeed, one thing that pundits of sustainability seem to agree on is that it is notoriously difficult to arrive at a broad consensus as to what sustainability actually looks like in practice. For this reason, it has variously been described as a "fuzzy" concept, a "buzz word," a "catch-all," a "wicked problem", and various other monikers bespeaking ambiguity (Phillis and Andriantiatsaholiniaina 2001; Kommadath et al. 2012; Pryshlakivsky and Searcy 2013; Weiner 2017). One likely cause of this conundrum lies in the widely popularized view of sustainability as a balance among three overlapping but otherwise distinct and sometimes even conflicting areas of concern - environment, society, and economy. This model offers no practical guidance as to how to prioritize among these spheres, resulting in seemingly unresolvable quandaries as to the relative importance of economic, social, and environmental considerations (Pelletier et al. 2014).

In a seminal contribution published in one of the early issues of the discipline's flagship journal Ecological 
Economics, Herman Daly proposed an alternative model for understanding sustainability that goes a considerable distance towards resolving such quandaries (Daly 1992). Daly posits that the economy must be viewed not as an independent entity but rather as a subsystem of society. In turn, society is a subsystem of the encompassing and supporting biophysical environment, which provides the conditions (i.e., stable biogeochemical cycles and ecosystem functioning, including the ecosystem goods and services we rely on) in which life, society, and economic activity become possible. According to this vision, achieving sustainability requires, at a minimum, the satisfaction of a nested hierarchy of three core criteria: (1) that the scale of our activities not exceed (and, as a result, erode) environmental carrying capacity (sometimes referred to as critical natural capital); (2) that, within this context, how and to whom the benefits and burdens of our activities accrue correspond to a shared understanding of distributive justice (within and between generations); and (3) that our allocation of scarce resources among competing economic activities be optimally efficient, so as to enable achieving our distributive objectives within the constraints posed by the overarching necessity of sustainable scale.

Life cycle assessment (LCA) is an increasingly popular ISO-standardized biophysical accounting framework used to characterize the inputs (material and energy resources), outputs (products and services), and wastes (emissions) per unit of a product/service provided, taking into account all relevant supply chain stages and activities. LCA is often described as a sustainability decision support tool. Yet, in practice, applications of LCA focus almost exclusively on eco-efficiency considerations (i.e., resource and emissions intensity per unit good or service) - an important but, in itself, limited aspect of sustainability (Castellani and Sala 2012; Garnett 2014; Bjorn et al. 2015, 2016; Pelletier et al. 2014; Pelletier 2015; Clift et al. 2017). Recent methodological proposals and developments in this field, however, seek to broaden the relevance of LCA results by relating the eco-efficiency measures made in LCA studies to planetary or regional sustainability boundaries (Pelletier and Tyedmers 2010; Bjorn and Hauschild 2015; Bjorn et al. 2015, 2016; Sandin et al. 2015). At the same time, others seek to improve the accessibility, communicability, and stakeholder relevance of information derived from LCA studies through the development of normalization and weighting schemes that support prioritizing among LCA indicator results (see Pizzol et al. 2017 and references therein). These are exciting but seemingly disparate developments from theoretical as well as practical perspectives. To date, these developments have not been unified with reference to an internally consistent understanding of the conditions necessary for sustainability, nor of LCA as a holistic, sustainability decision support tool that systematically addresses and prioritizes among such conditions. Here, we describe the potential role of Herman Daly's proposed ecological economic understanding of sustainability (and the corresponding conditions necessary to achieve it) in connecting the dots between traditional LCA and these areas of methodological development, which may allow for positioning LCA as a truly integrated sustainability decision support tool.

\section{Discussion}

\subsection{Herman Daly's three criteria for sustainability}

The first in the nested hierarchy of ecological economist Herman Daly's three criteria for sustainability (i.e., sustainable scale relative to biocapacity) flows from a basic appreciation of the implications of the second Law of Thermodynamics for sustainably managing human activities in a finite biosphere (Ayres 1998; Baumgartner et al. 2006). Simply put, all economic activities are ultimately made possible through the mobilization of limited material and energy resources, and inevitably emit wastes (entropy) into receiving environments with limited assimilatory capacity. As biological organisms are fundamentally dependent on the life support functions provided by our environment, the first necessary criterion for sustainability is therefore that the scale of throughput that underpins economic activity be limited so as to ensure that environmental carrying capacity is maintained (Santa-Barbara et al. 2005).

This recognition necessitates accepting that there are hard limits to both resource availability and waste assimilatory capacity, within which sustainable societies and economies must be structured. Once we accept the reality of such limits, and that the scale of our activities is already large relative to biocapacity (as evidenced, for example, by phenomena such as climate change, serial depletion of fish stocks, depletion of fossil energy resources) we are then faced with the inevitability of deciding how we should best allocate limited resources between potential competing uses - both within and between generations (Daly 1992). Hence, the second criterion for sustainability is that these decisions reflect a shared understanding of distributive justice (i.e., what we understand to be right or good with respect to economic outcomes) - which ultimately requires normative rather than purely objective decisions. Clearly, distributive considerations extend to a much broader suite of concerns than securing environmental integrity. However, from this perspective, ensuring environmental integrity takes primacy over social and economic issues. It becomes, in fact, the first principle of distributive justice because it constitutes the very foundation of human well-being (Pelletier 2010).

The third criterion for sustainability calls for the efficient allocation of these scarce resources such that we can most effectively achieve our distributive objectives within biophysical constraints (Daly 1992). This points towards a broader understanding of efficiency than that espoused in 
conventional economics - in particular, the incorporation of measures that capture the biophysical efficiency dimensions of economic activity (i.e., resource/emissions intensity per unit good or service). Such measures provide the necessary basis for comparing the extent to which different products, services, technologies, management decisions, or policies variously enable us to sustainably achieve our distributive objectives.

Here, we subsequently propose that (and describe how) this ecological-economic model for sustainability can serve to unify historical, as well as recent methodological developments and applications of LCA, and also clarify its potential for legitimately integrated sustainability decision support.

\subsection{Emergence and development of LCA as an eco-efficiency tool-and its limitations}

Life cycle assessment originated in the 1970 s as a tool to support the design and evaluation of eco-efficiency strategies in the context of industrial manufacturing and waste management (Baumman and Tillman 2004). It has enjoyed increasingly widespread application due to (1) its utility in determining the magnitude and distribution of resource use and emissions in interconnected industrial systems; (2) its multi-criteria nature, which supports its important role in identifying potential problem shifting due to implementation of product, management, or technology alternatives; and (3) its standardization by ISO, which promotes consistency and uniformity in practice. For these reasons, LCA has played an increasingly important role in the context of research, private sector initiatives, and policy instruments intended to advance sustainable production and consumption objectives (UNEP 2008; Pelletier et al. 2014; Sonneman et al. 2018).

However, despite its growing popularity, some commentators have cautioned against over-selling LCA as a sustainability decision support tool. Beyond the obvious limitations regarding life cycle inventory (LCI) data (i.e., with respect to quality, representativeness, and associated uncertainty) and LCA model reliability, such criticisms have, in large part, been motivated by the observation that measures of the resource and emissions intensity per unit of economic good or service provided, regardless of their rigor, are not in themselves sufficient for gauging whether or not a particular object of concern is, indeed, sustainable (Garnett 2014; Pelletier et al. 2014; Bjorn et al. 2016; Moltesen and Bjørn 2018). Critics point out that efficiency is a means to an end, rather than an end in itself, and efficiency measures mean little in the absence of a clear understanding of desired ends. Moreover, what constitutes efficiency and its relationship to sustainability may be defined in different ways from different perspectives and point towards different preferred courses of action with very different outcomes (Garnett 2014). Indeed, many of the counterintuitive conclusions that have been derived from LCA studies (for example, that organic food systems may not necessarily be better than their conventional counterparts, or that food miles often do not matter, or that reusable diapers may not be more resource efficient) are counter-intuitive precisely because they fly in the face of values and intuitions regarding sustainability that are not well-captured by standard, environmental life cycle assessment (Pelletier 2010).

In short, LCA (as it has been developed and largely applied) is clearly an effective tool in the sustainability managers toolbox for systematically considering some of the "efficiency" aspects of sustainability (Daly's third and subservient criterion) - an important, but ultimately limited consideration. However, recent methodological developments suggest that LCA may, in fact, be increasingly well-positioned to assume a much broader and more comprehensive role in sustainability decision support-in particular, when viewed through the lens of Daly's ecological economic understanding of sustainability. Specifically, this relates to (1) efforts to enable contextualizing and interpreting LCA "eco-efficiency" results with reference to sustainability boundaries, so as to support ensuring an environmentally sustainable scale of activities, and (2) the development of weighting methods that provide for prioritizing among sustainability indicators and, in turn, supporting consistent sustainability management decision-making based on biophysically constrained stakeholder-defined conceptions of distributive justice.

\subsection{LCA, normalization, and sustainable scale}

In order to make greater meaning of LCA results - in particular, the comparative relevance of the different kinds and levels of impacts that are calculated for product systems and what they imply for sustainability - it is helpful to contextualize the results as a basis for interpretation. In LCA, such contextualization is referred to as "normalization." Normalization, simply put, is the calculation of the relative importance of different LCIA results within a reference context. Historically, normalization sets were typically based on, for example, total emission levels for a country, region, time period, or population (Seppala and Hamalainen 2001; Seppala 2007). By dividing the calculated impacts (per functional unit) for the product system by the total reference impact levels for each impact category, the practitioner is able to understand the relative importance of the product system in contributing to overall impacts in the reference context. A notable criticism here, clearly, is that this implicitly treats all impact categories as if they are of equivalent importance, which might be considered a form of "passive weighting" (Finnveden 1999; SETAC 2002; Seppala and Hamalainen 2001; Seppälä 2007). Also of concern is the selection of reference context. Although the relevance from, for example, a domestic policy perspective may be clear, also clear is that the actual sustainability of an emission level for a product system is related to 
the extent to which it appropriates absolute carrying capacity (which, depending on impact category, may be local, regional, or globally defined) rather than its relationship to current emission levels observed within some arbitrarily selected reference context.

The concept of sustainable scale as a priority guiding principle for sustainability, as proposed by Daly (1992), has garnered considerable attention and popularization in recent years grace of the proposal of nine planetary boundaries that respectively define a "safe operating space" for humanity, along with best estimates of the current scale of human activities relative to these boundaries (Rockstrom et al. 2009; Steffen et al. 2015). It should be noted, however, that only two of these actually have global tipping points - the others should be considered at lesser geographical scales (Nordhaus et al. 2012). In a notable break from standard practice, several LCA researchers have since utilized such planetary boundaries (as well as more spatially resolved sustainability boundaries) as a basis for assessing (effectively normalizing) LCA results relative to carrying capacity. For example, Pelletier and Tyedmers (2010) used LCA-driven scenario models to assess the potential contribution of projected livestock production (beef, pork, and chicken, only) in 2050 to the appropriation of humanity's safe operating space with respect to GHG emissions, reactive nitrogen mobilization, and biomass appropriation. They found that, even assuming generous efficiency gains in livestock production over time, anticipated production levels in 2050 may account for $70 \%, 88 \%$, and $294 \%$ of our estimated safe operating space in these domains, respectively. Tuomisto et al. (2012) similarly used the safe operating space concept as a basis for comparing organic, conventional, and integrated farming systems. More recently, Bjorn and Hauschild (2015) advanced concrete methodological proposals for normalization of LCA results using per capita shares of ecological carrying capacity (Bjorn et al. 2015, 2016). This approach is equally applicable to assessing sustainable scale relative to global, regional, or local carrying capacity, provided that relevant capacities and aggregate loads are known (Bjorn et al. 2016). Bjorn et al. (2016) also propose principals for calculating "entitlement shares" to carrying capacity. Here, a studied system is considered to be environmentally sustainable provided that its indicator score (i.e., occupation of carrying capacity) does not exceed its carrying capacity entitlement. These recent developments, which enable linking LCA efficiency measures to sustainability boundaries, should be viewed as revolutionary for the field of LCA, since (by addressing Daly's first and third criteria) they bring the method much closer to realization as a true sustainability assessment tool.

\subsection{LCA and distributive justice-What are we weighting for?}

One of the key strengths of LCA is its multi-criteria nature, which enables simultaneous consideration of sustainability risks and opportunities across a range of relevant issue areas. Importantly, this also supports the identification and management of potential trade-offs that may arise with respect to one or more issue areas as a result of particular management interventions. Where LCA continues to fall short, however, is in providing structured guidance for systematic prioritization among valued outcomes. In other words, what matters most, and why, and how can this be consistently represented in decision-support contexts?

Such prioritization is challenging precisely because it often cannot be objectively resolved. Regardless of the rigor of LCA studies and our confidence in the hard numbers that they provide, we can often ultimately only make sense of those numbers on the basis of subjective judgements regarding what matters most. In other words, the necessary bridge between empirical LCA science and its application to sustainability management is an articulable vision of distributive justice that, when implemented, leads naturally to the kind of world we want.

Dealing with trade-offs based on value preferences can, however, be accommodated in LCA via the controversial practice of "weighting" (for reviews of relevant literature, see Bengsston and Stee 2000; Huppes and van Oers 2011; Pizzol et al. 2017). This involves applying weights to normalized life cycle impact assessment results based on the perceived relative importance of each impact category.

The ISO norm for LCA prohibits the use of weighting in publicly disclosed comparative studies - ostensibly out of a volition to prevent abuse of weighting (i.e., manipulating weights in order to achieve a favorable result for a particular product). While this concern can certainly be appreciated, decision makers are anyways inevitably tasked with weighing, balancing, and ultimately prioritizing among indicator results in order to make decisions that align with their particular mandates. In the least, weighting can help to render such decisionmaking transparent and systematic in place of more subjective, "gut feeling" driven decision-making. While it is clearly not the purview of LCA practitioners to decide on priorities, it would certainly be possible for practitioners to work with stakeholders in elucidating their priorities in order to provide weighted results.

One common approach to weighting that has been implemented historically in LCA is the "distant-to-target" method. In most applications, the ratios between current societal reference levels (i.e., aggregate contribution to impacts) and policy targets with respect to those impacts are used to weight impact assessment results. In other words, impacts are essentially ranked in order of importance based on the comparative distance between the societal reference level and the policy target (Wenzel et al. 1997; Lin et al. 2005). This approach is subject to a number of notable criticisms, including (1) that policy targets may not actually be sufficiently informed by credible science and conducive to sustainability, and (2) that it 
implicitly treats all kinds of impacts as having equivalent importance, for which an objective basis is lacking (Seppala and Hamalainen 2001).

In recent years, several authors in the LCA field have advanced proposals regarding weighting LCA results based on consideration of actual, biophysical sustainability thresholds or boundaries rather than political targets. For example, Sandin et al. (2015) described how normalization and weighting in LCA can be used to connect product-level LCA results to global scale sustainability challenges. Castellani et al. (2016) recommend extending policy-based distance-to-target weighting approaches to include carrying capacity/planetary boundaries-based approaches. Sala et al. (2016) review and present data, methods, and calculations for planetary boundaries-based weighting factors. From an ecological economic perspective, this approach is preferable to the policy-based distance-to-target approach, since it is predicated on normalizing and weighing results relative to actual, empirically-based estimates of biophysical sustainability thresholds. To the extent that transgression of any planetary scale sustainability boundary represents an existential threat to sustainable human well-being, there is clearly some merit in employing a distance-to-target approach. Nonetheless, the problematic assumption of equivalent importance of different sustainability boundaries remains. The assumption becomes more problematic still if a weighting approach is to be applied to sustainability boundaries at smaller geographical (for example, bioregional) scales.

The ecological economic model for sustainability proposed by Daly (1992) partially addresses the problem of weighting through the second "just distribution" criterion and its relationship to the overarching sustainable scale criterion. Ultimately, all relative sustainability indicator results (as produced in conventional environmental life cycle assessment) must be screened against a specific interpretation of distributive justice so as to enable prioritizing among them. However, Daly's ecological economic model itself, which gives primacy to the sustainable scale criterion, provides a strong basis for considerably reducing the subjectivity of weighting - at least for those indicator results that suggest exceedance of ecological carrying capacity, which would be assigned proportionately higher weights. Against this foil, management imperatives can be identified based first on the relative contribution of the product system to the potential erosion of carrying capacity, and secondarily so as to weigh and balance the rich suite of other sustainability indicators that need necessarily be accommodated in our decision-making. This includes, for example, indicators from social life cycle assessment, life cycle costing, and other decision support tools (Pelletier 2010; Pelletier et al. 2014). In contrast to carrying capacity-based indicators, the latter indicators must be developed so as to reflect either internationally accepted norms (for example, ILO labor standards) and/or context/stakeholder-specific value preferences. The application of "entitlement shares" similarly enables context-appropriate expression of value preferences within scale-based constraints to the extent that these reflect prioritization among goods/services or between stakeholder groups (Bjorn et al. 2015, 2016). The literature regarding deliberative democratic processes is illustrative of one, increasingly mainstream approach to value elicitation and prioritization in support of transparent decision-making that can used in order to develop weighting schemes. Deliberative democracy advocates for communication and deliberation among stakeholders in order to reach consensus (Zografos and Howarth 2010). This is applicable to the process of weighting in multi-criteria environmental decision-making, since it can increase both the transparency and legitimacy of the decision-making process.

\section{Conclusions and future directions}

The ecological economic model for sustainability, as proposed by Daly (1992), provides a practical foundation for, in the least, beginning to satisfactorily answer the quintessential question "what is sustainability?" (and, pertinent to LCA, "what is the most sustainable alternative?"). By repositioning the traditional three spheres of sustainability (i.e., environmental, social, and economic) as a nested hierarchy respectively addressing sustainable scale (relative to biocapacity), distributive justice, and efficient allocation, prioritizing among them on a consistent basis becomes possible. In turn, this model also supports a reinterpretation of LCA as a true sustainability decision support tool, in particular by enabling unification of historical development/practice with recent methodological developments.

To date, LCA has been primarily used to measure and improve the resource and environmental efficiency of interlinked industrial production systems. Efficiency, however, is not commensurate with sustainability - although it may certainly provide an important means towards achieving more sustainable outcomes. Building on recent methodological developments with respect to normalization and weighting of LCA results using carrying capacity measures, practitioners can now increasingly relate and assess efficiency-based results against global, regional or local sustainability boundariesalthough substantial work does remain to enable robust and consistent implementation of sustainability boundaries in LCA studies (Ryberg et al. 2016). For example, Clift et al. (2017) describe the need for common metrics and distanceto-boundary measures that are relevant at multiple scales, rigorous data and models, and improved understanding of potential interactions between different sustainability boundaries. In essence, however, these developments extend LCA from an eco-efficiency tool to one that can address both the first 
(sustainable scale) and third (efficient allocation) criteria for sustainability.

Addressing distributive justice (the second sustainability criterion) requires prioritizing among efficiency strategies in a way that is consistent with a normative vision of how the world ought to be. This is commensurate with the controversial practice of weighting in LCA. What the ecological economic perspective brings to weighting is an internally consistent rationale for prioritizing among environmental sustainability indicators, as well as for prioritizing such indicators over socio-economic sustainability indicators - in particular, for indicator results that suggest potential erosion of ecological carrying capacity. This is based on the recognition that humanity's sustainability cannot be secured so long as our activities transgress environmental sustainability boundaries. Simply put, ecological carrying capacity cannot be traded off for gains in social or economic sustainability, since this would ultimately anyways undermine the context within which socio-economic well-being becomes possible. There clearly remains, however, ample scope (and, indeed, need) for weighting in order to also prioritize among the multiple other sustainability indicators that might be considered in LCA studies (including social LCA and life cycle costing - in particular when externalities are included). In the absence of clear international norms, these latter criteria must be weighted so as to reflect context- and stakeholder-specific values. Such weighting can enable consistent, context-appropriate sustainability decision support on an articulable and justifiable basis.

Acknowledgements This work was supported by funding from the Natural Sciences and Engineering Council of Canada (NSERC) and Egg Farmers of Canada (EFC) through the NSERC/EFC Research Chair in Sustainability.

Open Access This article is distributed under the terms of the Creative Commons Attribution 4.0 International License (http:// creativecommons.org/licenses/by/4.0/), which permits unrestricted use, distribution, and reproduction in any medium, provided you give appropriate credit to the original author(s) and the source, provide a link to the Creative Commons license, and indicate if changes were made.

\section{References}

Ayres R (1998) Eco-thermodynamics: economics and the second law. Ecol Econ 26:189-209

Baumgartner S, Faber M, Schiller J (2006) Joint production and ecological economics: on the foundations of environmental policy. Edward Elgar, Northampton

Baumman H, Tillman A (2004) The hitch hiker's guide to LCA: an orientation in life cycle assessment methodology and application. Studentlitteratur, Lund

Bengsston M, Stee B (2000) Weighting in LCA - approaches and applications. Environ Prog 19(2):101-109

Bjorn A, Hauschild M (2015) Introducing carrying capacity-based normalisation in LCA: framework and development of references at midpoint level. Int J Life Cycle Assess 20(7):1005-1018
Bjorn A, Diamond M, Owsianiak M, Verzat B, Hauschild M (2015) Strengthening the link between life cycle assessment and indicators for absolute sustainability to support development within planetary boundaries. Environ Sci Technol 49:6370-6371

Bjorn A, Margin M, Roy PO, Bulle C, Hauschild M (2016) A proposal to measure absolute environmental sustainability in life cycle assessment. Ecol Indic 63:1-13

Castellani V, Sala S (2012) Ecological footprint and life cycle assessment in the sustainability assessment of tourism activities. Ecol Indic 6: 135-147

Castellani V, Benini L, Sala S, Pant R (2016) A distance-to-target weighting method for Europe 2020. Int J Life Cycle Assess 21(8): 1159-1169

Clift R, Sim S, King H, Chenoweth J, Christie I, Clavreul J, Mueller C, Posthuma L, Boulay AM, Chaplin-Kramer R, Chatterton J, DeClerck F, Druckman A, France C, Franco A, Gerten D, Goedkoop M, Hauschild M, Huijbregts M, Koellner T, Lambin E, Lee J, Mair S, Marshall S, McLachlan M, Milà i Canals L, Mitchell C, Price E, Rockström J, Suckling J, Murphy R (2017) The challenges of applying planetary boundaries as a basis for strategic decision-making in companies with global supply chains. Sustainability 9:279

Daly H (1992) Allocation, distribution, and scale: towards an economics that is efficient, just, and sustainable. Ecol Econ 6(3):185-193

Finnveden G (1999) A critical review of operational valuation /weighting methods for life cycle assessment. AFR report 253. AFN, Naturvårdsverket, Stockholm

Garnett T (2014) Three perspectives on sustainable food security: efficiency, demand restraint, food system transformation: what role for life cycle assessment? J Clean Prod 73:10-18

Huppes G, van Oer L (2011) Background review of existing weighting approaches in life cycle impact assessment. JRC Scientific and Technical Reports, European Commission, Brussels

Kommadath B, Sarkar R, Rath B (2012) A fuzzy logic based approach to asses sustainable development of the mining and minerals sector. Sustain Dev 20:386-399

Lin M, Zhang S, Chen Y (2005) Distance-to-target weighting in life cycle impact assessment based on Chinese environmental policy for the period 1995-2005. Int J Life Cycle Assess 10(6):393-398

Moltesen A, Bjørn A (2018) LCA and sustainability. In: Hauschild M, Rosenbaum RK, Olsen S (eds) Life cycle assessment: theory and practice. Springer, pp 43-55

Nordhaus T, Shellenberger M, Blomqvist L (2012) The planetary boundaries hypothesis: a review of the evidence. The Breakthrough Institute, Oakland

Pelletier N (2010) Environmental sustainability as the first principle of distributive justice: towards a communitarian-based normative foundation for ecological economics. Ecol Econ 69(10):1887-1894

Pelletier N, Tyedmers P (2010) Forecasting potential global environmental costs of livestock production 2000-2050. Proc Natl Acad Sci U S A 107(43):18371-18374

Pelletier N, Maas R, Goralcyk M, Wolf MA (2014) Conceptual basis for the European Sustainability Footprint: towards a new policy assessment framework. Environ Dev 9:12-23

Pelletier N (2015) Life Cycle Thinking, Measurement and Management for Food System Sustainability. Environ Sci Technol 49(13):75159. https://doi.org/10.1021/acs.est.5b00441

Phillis Y, Andriantiatsaholiniaina L (2001) Sustainability: an ill-defined concept and its assessment using fuzzy logic. Ecol Econ 37:435-456

Pizzol M, Laurent A, Sala S, Weidema B, Verones F (2017) Normalization and weighting in life cycle assessment: quo vadis? Int J Life Cycle Assess 22:853-866

Pryshlakivsky J, Searcy C (2013) Sustainable development as a wicked problem. In: Kovacic S, Sousa-Poza A (eds) Managing and engineering in complex situations. Topics in safety, risk, reliability and quality, vol 21. Springer, Dordrecht 
Rockstrom J, Steffen W, Noone K et al (2009) A safe operating space for humanity. Nature 461:472-475

Ryberg M, Owsianiak M, Richardson K, Hauschild M (2016) Challenges in implementing a planetary boundaries-based life cycle impact assessment methodology. J Clean Prod 139:450-459

Sala S, Benini L, Crenna E, Secchi M (2016) Global environmental impacts and planetary boundaries in LCA. EUR $28371 \mathrm{EN}$; JRC Technical Report; European Commission, Luxembourg

Sandin G, Peters G, Svanstrom M (2015) Using the planetary boundaries framework for setting impact-reduction targets in LCA contexts. Int J Life Cycle Assess 20(12):1684-1700

Santa-Barbara J, Czech B, Daly H, Farley J, Malghan D (2005) Sustainable scale in environmental education: three rules, two perspectives, one overriding policy objective, and six cultural shifts. Proceedings of the Centre for Environment Education 2005 Conference, Ahemedabad, Gujurat, India

Seppälä J (2007) On the meaning of fuzzy approach and normalisation in life cycle impact assessment. Int J Life Cycle Assess 12(7):464-469

Seppala J, Hamalainen R (2001) On the meaning of the distance-to-target weighting method and normalization in life cycle impact assessment. Int J Life Cycle Assess 6:211-218

SETAC (2002) Life cycle impact assessment: striving towards best practice. Edited by Udo de Haes HA et al. Society of Environmental Toxicology and Chemistry, Brussels
Sonneman G et al (2018) Life cycle thinking and the use of LCA in policies around the world. In: Hauschild M, Rosenbaum R, Olsen $\mathrm{S}$ (eds) Life cycle assessment. Springer, Cham

Steffen W, Richardson K, Rockström J et al (2015) Planetary boundaries: guiding human development on a changing planet. Science 347(6223):736-746

Tuomisto H, Hodge I, Riordan P, Macdonald D (2012) Exploring a safe operating approach to weighting in life cycle impact assessment - a case study or organic, conventional and integrated farming systems. J Clean Prod 37:147-153

UNEP (2008) The life cycle initiative. United Nations Environment Program. http://lcinitiative.unep.fr/. Accessed Jan 2018

Weiner J (2017) Applying plant ecological knowledge to increase agricultural sustainability. J Ecol 105:865-870

Wenzel H, Hauschild M, Alting L (1997) Environmental assessment of products. Vol. 1: methodology, tools and case studies in product development. Chapman \& Hall, London

Zografos C, Howarth RB (2010) Deliberative ecological economics for sustainability governance. Sustainability 2(11):3399-3417

Publisher's note Springer Nature remains neutral with regard to jurisdictional claims in published maps and institutional affiliations. 